\title{
Dor Crônica: compreensão do idoso oncológico hospitalizado e suas estratégias de enfrentamento
}

\author{
Chronic pain: perception of elderly cancer patients in hospital \\ and their coping strategies
}

\author{
Naylana Rute da Paixão Santos' ${ }^{1}$, Martha Moreira Cavalcante Castro² \\ 1Autor para correspondência. Universidade Federal da Bahia. Salvador, Bahia, Brasil. ORCID: 0000-0003-4997-6920. naylanarute@hotmail.com \\ 2Universidade Federal da Bahia, Escola Bahiana de Medicina e Saúde Pública. Salvador, Bahia, Brasil. \\ ORCID: 0000-0002-2968-9206. marthamccastro@gmail.com
}

\begin{abstract}
RESUMO | A dor é uma experiência multidimensional que gera desconforto físico e desencadeia muitas respostas afetivas e emocionais. Na população idosa a prevalência de dor é elevada, e dentro da oncologia a dor é o sintoma mais frequente e de difícil controle. Considerando que a dor crônica na população geriátrica evidencia-se enquanto uma situação estressora, e há uma grande variabilidade na forma de enfrentar tais situações, o presente estudo tem como objetivo analisar a percepção do idoso oncológico hospitalizado e as estratégias de enfrentamento utilizadas por este diante da dor crônica. Trata-se de um estudo exploratório, de natureza qualitativa e descritiva, através do qual foi realizado estudo de caso com cinco participantes. Foi utilizada a técnica de entrevista semiestruturada e a análise dos dados foi realizada segundo o método de Análise de Conteúdo de Bardin. Os resultados destacaram que os participantes significam a experiência de dor como uma vivência negativa, gerando e intensificando o isolamento e sentimentos de irritação, bem como evidenciaram a religiosidade e a espiritualidade enquanto principais estratégias para minimizar os impactos negativos advindos do adoecimento e tratamentos contínuos. $O$ entendimento da maneira de enfrentamento da dor pode auxiliar profissionais de saúde na análise de fatores que influenciam na mesma, assim como na adequação de possíveis estratégias de enfrentamento disfuncionais no contexto de saúde, auxiliando o idoso no tratamento e em sua qualidade de vida.
\end{abstract}

\begin{abstract}
The pain is a multidimensional experience that generates physical discomfort and triggers many affective and emotional responses. In the elderly population the prevalence of pain is high, and within the Oncology pain is the most frequent symptom and difficult to control. Whereas chronic pain in the geriatric population is evidenced as a estressora situation, and there is a great variability in the shape to face such situations, this study aims to analyze the perception of the elderly hospitalized cancer and coping strategies used by this on chronic pain. This is an exploratory study, qualitative and descriptive in nature, through which was conducted five case study participants. It was used the semi-structured interview technique and the analysis of the data was performed by the method of content Analysis of Bardin. The results highlighted that the participants mean the experience of pain as a negative experience, generating and intensifying the isolation and feelings of irritation, as well as highlighted the religiosity and spirituality while main strategies to minimize negative impacts arising from illness and ongoing treatments. Understanding the way to confront pain can assist health professionals in the analysis of factors influencing on same, as well as the appropriateness of possible strategies of dysfunctional coping in the context of health, assisting the elderly in treatment and in your quality of life.
\end{abstract}

KEYWORDS: Chronic pain. Elderly cancer. Coping strategies.

PALAVRAS-CHAVE: Dor crônica. Idoso oncológico. Estratégias de enfrentamento. 


\section{Introdução}

Segundo a Associação Internacional para o Estudo da Dor (IASP), dor é uma experiência sensorial e emocional desagradável, decorrente da lesão real ou potencial dos tecidos do organismo (IASP, 2007). Trata-se de uma manifestação subjetiva que varia de indivíduo para indivíduo e apresenta múltiplas dimensões (Angerami-Camon, 2012). Há inúmeras formas de classificar a dor e quanto à duração ela pode ser dividida entre aguda ou crônica.

A dor aguda é o processo de dor com períodos curtos, que podem durar de minutos a semanas. Os receptores da dor envolvem extremidades de nervos na pele e sua evolução, de modo geral, é a redução gradual da intensidade, até a remissão da sensação dolorosa (Angerami-Camon, 2012; Sallum, Garcia \& Sanches, 2012). A dor crônica, por sua vez, caracteriza-se pela persistência do quadro álgico, que pode variar de meses a anos. A literatura aponta um tempo igual ou superior a três meses de vigência da dor, para ser classificada como crônica (Angerami-Camon, 2012; Loduca et al., 2014).

Segundo Dellaroza et al. (2008), como finalidade de pesquisa, a IASP preconiza a dor crônica como aquela com duração maior que seis meses, de caráter contínuo ou recorrente. Geralmente está relacionada a lesões já diagnosticadas e tratadas, bem como a doenças consideradas crônicas e até irreversíveis. Neste sentido, no caso da dor crônica, pode ou não haver uma correlação entre dor e lesão. Em virtude da ativação de diferentes vias neuronais de modo prolongado, a natureza da dor pode mudar e a dor aguda pode vir a se cronificar (Sallum, Garcia \& Sanches, 2012; Lima \& Trad, 2008).

A duração prolongada da dor crônica pode fazer com que a dor enquanto sintoma transforme-se na própria doença, em virtude da sua natureza perturbadora, causando impactos nos hábitos de vida, modificação do humor, alterações nas relações familiares, sociais, de trabalho e lazer (Castro et al., 2011). Também se constitui como um problema de saúde pública, devido a sua prevalência, alto custo e impacto negativo que pode ser gerado na qualidade de vida, tanto dos pacientes como de seus familiares (Salvetti \& Pimenta, 2007). A avaliação da dor crônica é mais complexa em relação à dor aguda, pois envolve componentes comportamentais, cognitivos, afetivos, sociais, crenças, expectativas, valores, entre outros aspectos (Sallum, Garcia \& Sanches, 2012).

Na população idosa a prevalência de dor é elevada, tendo a dor crônica uma porcentagem que varia entre 29,7 a $89,9 \%$. Assim como ocorre em outros sistemas do corpo humano, o envelhecimento promove alterações no sistema nervoso, alterando o processamento, a percepção e o tratamento da dor. Algumas queixas do idoso relacionadas à dor são atribuídas à idade e consideradas próprias ao processo de enveIhecimento deixando, assim, de ser tratadas, influenciando negativamente a qualidade de vida na velhice (Celich \& Galon, 2009; Pereira et al., 2014).

Entre as dores mais comuns nos idosos, encontram-se as de origem musculoesqueléticas, seguidas das dores neuropáticas e as dores oncológicas, que por sua vez configuram-se como dores crônicas (Chiba \& Ashmawi, 2011). A distribuição dos diferentes tipos de câncer sugere uma transição epidemiológica em andamento. Com o crescimento exponencial de idosos, é possível identificar um aumento expressivo na prevalência do câncer, o que demanda dos gestores do Sistema Único de Saúde (SUS) um esforço para a oferta de atenção adequada aos doentes (Ministério da Saúde, 2006).

A idade se torna um fator de risco para o desenvolvimento de câncer devido à duração da carcinogênese, à vulnerabilidade dos tecidos do idoso aos carcinógenos ambientais e as demais transformações que favorecem o desenvolvimento e crescimento de tumores, embora as neoplasias malignas sejam prevalentes em qualquer faixa etária (Duarte \& Nogueira-Costa, 2011). Pacientes geriátricos oncológicos frequentemente apresentam comorbidades, reserva fisiológica restrita e limitações funcionais, requerendo dos profissionais de saúde, tomadas de decisões terapêuticas planejadas e singulares (Reticena, Beuter \& Sales, 2015).

Portanto, os profissionais envolvidos com pacientes portadores de dor crônica devem considerar a interferência de fatores cognitivos e psicossociais na precipitação e manutenção da dor, avaliando os impactos físicos, psíquicos e sociais do adoecimento e tratamento (Duarte \& Nogueira-Costa, 2011; Lima \& Trad, 2008). Os indivíduos podem encarar com dificuldade os eventos que podem desenvolver a resposta de dor, agravando a intensidade desta e gerando o estresse. Os estressores dizem respeito às condições que afetam o 
organismo, sendo a dor uma destas condições, requerendo deste, respostas adaptativas para lidar com o seu adoecimento (Angerami-Camon, 2012).

Na perspectiva de Lazarus e Folkman (1984), as habilidades desenvolvidas para lidar com situações de estresse e adaptação são formas de enfrentamento (coping), que envolvem o conjunto de estratégias cognitivas e comportamentais utilizadas para avaliar e gerenciar as exigências internas e/ou externas. Deste modo, tais estratégias de enfrentamento correspondem ao processo pelo qual o indivíduo administra as demandas da relação pessoa/ambiente, e as emoções que elas geram. Diante da situação considerada estressora, os indivíduos realizam uma avaliação do que está ocorrendo, e gera uma resposta, na tentativa de solucionar e/ou amenizar tal situação.

Tais estratégias permitem ao indivíduo rever novas formas de pensar e se comportar ao se deparar com situações estressoras, com base em suas avaliações e reavaliações e isto, pode gerar como consequência, resultados mais ou menos adaptativos ao rever a situação inicial. $O$ enfrentamento pode ser centralizado no problema, cujo objetivo é alterar a dificuldade existente na relação entre a pessoa e o ambiente, direcionando sua ação interna ou externamente; ou centralizado na emoção, cujo objetivo é alterar o estado emocional do indivíduo, buscando reduzir a sensação desagradável do estado de estresse (Vivan \& Argimon, 2009). Conforme pontuam Horta, Ferreira e Zhao (2010), há uma variabilidade na forma de enfrentar as situações estressoras. No que tange a experiência de dor crônica na população geriátrica, especialmente em pacientes oncológicos, a incipiência de estratégias pode conduzir à perda da qualidade de vida, bem como pode gerar depressão, ansiedade e isolamento social.

Deste modo, o presente estudo teve como objetivo analisar a percepção do idoso oncológico hospitalizado e as estratégias de enfrentamento utilizadas por este diante do seu quadro de dor. Enquanto objetivos específicos pretendeu-se conhecer a percepção do idoso hospitalizado sobre a dor crônica, bem como analisar a relação entre a forma como o indivíduo percebe a dor e as estratégias que utiliza.

Este estudo apresenta relevância social e acadêmica considerando não somente o crescimento demográfico exponencial da população idosa brasileira, mas também devido aos impactos físicos, psíquicos e sociais da dor crônica nesta população específica, fato que demanda ações que minimizem as consequências negativas advindas desta cronicidade. Além disto, é relevante considerar a percepção do próprio sujeito, neste caso, o idoso, dado que suas narrativas podem fornecer aspectos importantes sobre suas vivências, e possíveis estratégias que podem ser utilizadas no manejo da dor, no processo de hospitalização e nos cuidados integrais ao idoso oncológico.

\section{Método}

\section{Tipo de Estudo}

O presente estudo é de natureza qualitativa, caráter exploratório e descritivo. Esse tipo de pesquisa procura explorar o universo de significados e sentimentos, permitindo compreender a realidade vivenciada. A pesquisa descritiva observa, registra, analisa e relaciona fatos ou fenômenos, buscando conhecer valores, princípios e crenças do indivíduo (Minayo, 2010).

\section{Local}

O estudo foi realizado em uma unidade oncológica de um hospital filantrópico voltado para usuários da rede SUS, no município de Salvador - BA. Este campo de pesquisa é um dos locais de prática do Programa de Residência Multiprofissional em Atenção à Saúde da Pessoa Idosa, modalidade de especialização, onde o presente estudo se originou. A coleta de dados ocorreu entre os meses de Novembro e Dezembro de 2016.

\section{Participantes}

Foram selecionados cinco participantes idosos para a realização deste estudo. Essa quantidade ficou definida após o critério de saturação de dados. Foi utilizado como critérios de inclusão indivíduos com idade igual ou acima de 60 anos; estar internado na referida unidade oncológica do hospital; ter diagnóstico de dor crônica registrado em prontuário e não possuir alteração cognitiva que impossibilitasse a realização das entrevistas. Todos os participantes escolhidos preenchiam os critérios de inclusão para participação no estudo. 


\section{Instrumentos e procedimentos}

A coleta de dados foi obtida por meio da técnica de entrevista semiestruturada. Esta é caracterizada por um diálogo com o entrevistado, partindo de questões previamente elaboradas, sendo complementadas por outras inerentes às circunstâncias momentâneas à entrevista e flexível às adaptações do entrevistado (Minayo, 2010).

A primeira parte do roteiro continha dados sociodemográficos, seguidos de questões relacionadas à história do adoecimento, diagnóstico, tratamento oncológico, percepção sobre dor e estratégias de enfrentamento utilizadas. Dentre as questões elaboradas para este estudo incluíam-se as seguintes, relacionadas ao histórico do adoecimento: "Qual seu diagnóstico?", "Há quanto tempo tem o diagnóstico?", "Já fez algum tratamento anterior?", "Qual tratamento faz atualmente?", "Há quanto tempo o Sr./ Sra está internado (a)?" "Conte-me sua história de adoecimento."

No que se refere a dor, as questões eram basicamente: "Para você, o que é dor?" "Você atribui essa dor a algo específico?", "Há quanto tempo sente dor?", "Como se iniciaram as dores?" "Qual a localização da dor?", " Existe algum fator que intensifica/ melhora a dor?", "Quais sentimentos você tem no momento de dor?". Quanto às estratégias de enfrentamento: "No momento da dor, você faz algo para aliviá-la ou diminui-la? Se sim, o que?", "Existe algum pensamento que o auxilia a lidar com a dor?", "Existe alguma crença pessoal/religiosa que o ajuda a lidar com a experiência de dor?". Essas questões eram acrescidas de outras, conforme as respostas dos participantes e andamento da entrevista.

As entrevistas foram realizadas individualmente na referida unidade oncológica, e dado o quadro clínico dos entrevistados, aconteceram nas enfermarias, respeitando as normas e rotinas dos atendimentos multiprofissionais oferecidos aos pacientes. Cada entrevista foi gravada, com o auxílio de um gravador digital, durando em média 30 minutos, sendo, posteriormente transcrita, na íntegra, pela pesquisadora. Nenhum dos participantes se recusou a participar deste estudo.

\section{Análise dos dados}

A análise foi realizada segundo o método de Análise de Conteúdo de Bardin, que possibilita a descoberta do significado da mensagem contida no texto, resultando em atender aos objetivos propostos no estudo. A Análise de Conteúdo é um conjunto de técnicas de análise das comunicações que visa obter, por procedimentos sistemáticos, indicadores que permitam a inferência de conhecimentos relativos às condições de produção/recepção destas mensagens (Bardin, 2011).

As fases de análise foram seguidas de acordo com os três polos de organização propostos por Bardin: a pré análise; a exploração do material; o tratamento dos resultados, inferência e interpretação (Bardin, 2011). Após coleta dos dados e transcrição das entrevistas, foi realizada uma leitura flutuante, para captar o conteúdo de forma genérica. Nas leituras sucessivas, os pontos chaves das falas de cada participante foram destacados, conforme pertinência e objetivos do estudo. Em seguida, as falas foram agrupadas conforme representatividade e de acordo a semelhança e relevância do conteúdo apresentado. Por fim, foram organizadas categorias analíticas que foram discutidas baseando-se na literatura sobre o tema.

\section{Aspectos Éticos}

Para garantia da ética em pesquisa, o projeto deste estudo foi submetido e avaliado pelo Comitê de Ética e Pesquisa (CEP) da instituição que foi campo de prática para a presente pesquisa, com aprovação sob o parecer de $n^{\circ}$ 1.813.073 (CAAE 58199816.0.0000.0047). Os participantes da pesquisa foram esclarecidos quanto aos objetivos do trabalho, ficando livres para participarem ou não, assegurando-lhes a liberdade de desistir de sua participação a qualquer momento. Após leitura, entendimento dos objetivos do estudo e aceitação, os participantes assinaram o Termo de Consentimento Livre e Esclarecido (TCLE), sendo respeitados os princípios éticos que constam na resolução 466/12 do Conselho Nacional de Saúde, que regulamenta a pesquisa envolvendo seres humanos (Brasil, 2013).

Os padrões de sigilo dos participantes foram mantidos, de modo a evitar qualquer exposição ou situação vexatória. Para garantir o anonimato, no presente estudo os participantes foram identificados com nomes de pedras preciosas, preservando, assim, as informações prestadas. Os mesmos foram informados que este estudo não traria riscos físicos ou químicos, no entanto, poderia gerar desconforto ou incômodo em compartilhar informações pessoais ou confidenciais 
em alguns tópicos do questionário e que, neste caso, os mesmos seriam assistidos pelo serviço de psicologia da referida unidade.

\section{Resultados e discussão}

Foram entrevistados cinco idosos, sendo dois homens e três mulheres, cujas idades variaram entre 60 a 66 anos. Quanto ao estado civil, dois eram divorciados, uma casada, um solteiro e uma viúva. Os participantes eram adeptos a diferentes religiões, entre estas a católica, evangélica, budista e espírita. O grau de escolaridade variou de $1^{\circ}$ incompleto até o $2^{\circ}$ grau completo. Todos tinham conhecimento diagnóstico e o tempo com dor crônica variou de seis meses a cinco anos. A caracterização dos participantes e dados sociodemográficos podem ser observados no Quadro 1 abaixo:

Quadro 1. Dados sociodemográficos e de saúde dos participantes

\begin{tabular}{|c|c|c|c|c|c|c|c|c|c|c|}
\hline Codinome & Sexo & Idade & Estado Civil & Filhos & Escolaridade & Ocupação & Religião & Diagnóstico & Tempo/Dor & $\begin{array}{l}\text { Tempo de internamento } \\
\text { (até a data da entrevista) }\end{array}$ \\
\hline Ametista & $\mathrm{F}$ & 66 & Viúva & 4 & $\begin{array}{c}1^{\circ} \mathrm{grau} \\
\text { incompleto }\end{array}$ & $\begin{array}{l}\text { Doméstica } \\
\text { aposentada }\end{array}$ & Católica & $\begin{array}{l}\text { Neoplasia de canal } \\
\text { anal }\end{array}$ & $\begin{array}{c}1 \text { ano e } 2 \\
\text { meses }\end{array}$ & 20 dias \\
\hline Esmeralda & $\mathrm{F}$ & 62 & Divorciada & 9 & $\begin{array}{l}2^{\circ} \text { grau } \\
\text { completo }\end{array}$ & $\begin{array}{l}\text { Doméstica } \\
\text { aposentada }\end{array}$ & Evangélica & $\begin{array}{c}\text { Neoplasia de colo } \\
\text { uterino }\end{array}$ & 6 meses & 5 dias \\
\hline Urânio & M & 64 & Solteiro & 1 & $\begin{array}{l}2^{\circ} \text { grau } \\
\text { completo }\end{array}$ & $\begin{array}{l}\text { Bancário } \\
\text { aposentado }\end{array}$ & $\begin{array}{c}\text { Católico e } \\
\text { simpatizante } \\
\text { do Espiritismo }\end{array}$ & $\begin{array}{l}\text { Carcinoma de base } \\
\text { de língua e epiglote }\end{array}$ & 2 anos & 12 dias \\
\hline Magnetita & $\mathrm{F}$ & 60 & Casada & 7 & $\begin{array}{c}1^{\circ} \mathrm{grau} \\
\text { incompleto }\end{array}$ & $\begin{array}{l}\text { Doméstica } \\
\text { aposentada }\end{array}$ & Evangélica & $\begin{array}{l}\text { Neoplasia de } \\
\text { estômago (com } \\
\text { metástase p/ fígado } \\
\text { e pâncreas) }\end{array}$ & 5 anos & 6 dias \\
\hline Ametrino & $\mathrm{M}$ & 66 & Divorciado & 5 & $\begin{array}{c}2^{\circ} \text { grau } \\
\text { incompleto }\end{array}$ & $\begin{array}{l}\text { Eletricista } \\
\text { aposentado }\end{array}$ & Budista & $\begin{array}{l}\text { Adenocarcinoma de } \\
\text { esôfago (metástase } \\
\text { óssea e p/ fígado) }\end{array}$ & 10 meses & 50 dias \\
\hline
\end{tabular}


Durante a análise das entrevistas, foram identificados três grandes temas que permearam e predominaram as narrativas dos participantes, os quais serão apresentados como categorias analíticas: "Percepção e significação da dor: múltiplos olhares"; "Dor, solidão e isolamento: uma via de mão dupla" e, por fim, "Dor, religiosidade e espiritualidade: uma busca de caminho fora da ciência".

\section{Percepção e Significação da Dor: Múltiplos Olhares}

A amplitude conceitual de dor envolve aspectos multidimensionais e, portanto, a dor sentida envolve corpo, mente, história de vida e é carregada de significados por quem a vivencia (Lima \& Trad, 2008). Sustentar tais significados é uma experiência que envolve sensações e sentimentos que influenciam na relação que o sujeito estabelece consigo e com os outros (Palmeira, 2015).

A compreensão da vivência álgica é importante na abordagem da dor nas práticas de saúde coletiva, uma vez que permite aos profissionais construírem o entendimento sobre as narrativas de dor auxiliando, assim, nas condutas terapêuticas (Santos, Giancomin \& Firmo, 2015). Aquele que experimenta a dor pode sofrer o rompimento com várias dimensões importantes da sua vida. Portanto, valorizar as reflexões produzidas por quem sente a dor, pode ajudar a resgatar a dimensão de autonomia desses sujeitos, interferindo na sua identidade e nos significados relacionados à dor (Palmeira et al., 2015). Nos relatos dos participantes, as percepções sobre dor, de um modo geral, remetem a conotações negativas, envolvendo as perdas a ela associadas, bem como a ausência de felicidade e bem estar, conforme é expresso a seguir:

Ah... dor é uma coisa ruim, uma coisa muito ruim. É uma coisa que não devia existir em ninguém, porque é o que eu acho, né? Sem dor, você tá no céu, você é uma pessoa feliz, saudável, você se sente que é gente, sei lá, você sente tudo de bom (Ametista, 66 anos).

Quanto a este aspecto o paciente Urânio também reforça o caráter negativo da dor ao afirmar: "Dor dói, é muito ruim". Ametrino ainda acrescenta ao caráter negativo da dor, a necessidade de buscar soluções para enfrentá-la: "Dor é um sintoma, extra normal, que você não está acostumado a sentir e que é incômodo, obrigando a gente a ir buscar ajuda, né?".
Conforme discutem Santos, Giancomin e Firmo (2015), cada grupo social tem uma linguagem singular por meio da qual as pessoas enfermas demonstram para as outras os sentidos daquilo que as fazem sofrer. Segundo estes mesmos autores, no campo de fala dos idosos, é recorrente a saúde estar relacionada a uma vivência de ausência de dor e, por sua vez, a doença ser interpretada como a dor sentida no próprio corpo envelhecido. Embora os participantes do estudo não tragam a noção de envelhecimento atrelada a dor, pontuam sobre a dimensão de sofrimento atrelada a experiência dolorosa, bem como os incômodos advindos da mesma.

As atividades diárias ganham outra conotação no universo daquele que convive com a dor crônica, bem como influencia diretamente nos aspectos emocionais do sujeito, como explicitado pela paciente Magnetita ao afirmar que "a dor ataca até a cabeça da gente", referindo-se aos sentimentos negativos como o nervoso e a irritação decorrentes da vivência álgica. Portanto, as relações que se estabelecem são mediadas pela sensação dolorosa e por diversos sentimentos, incluindo irritação, cansaço e tristeza (Castro et al., 2011)

Estes aspectos emocionais são retratados pelos pacientes que percebem o quanto a dor influencia nas emoções e afetos, como é expresso por Ametista: "Às vezes com a dor, ficava assim muito nervosa, muito mesmo, não queria falar com ninguém, ficava muito triste, pra baixo". Magnetita também pontua este aspecto ao relatar: "Fico sem paciência, não guento ninguém chegar, encher a casa e conversar e fazer zoada, num guento mesmo, fico estressada". Tal aspecto, ainda é enfatizado na narrativa abaixo:

Ah, a dor me dá irritação, nervoso... até a voz das pessoas me incomoda. E mando ficar calado! Se ficar perguntando se tá com dor, se passou, se aumentou, vai resolver? Por exemplo, eu tô aqui com você que acabou de me dar uma injeção pra dor, aí fica assim: 'E aí melhorou, passou mais?' Aí eu mando calar a boca porque ... vai resolver? Se eu disser que aumentou a dor, vai resolver? Se eu disser que diminuiu, vai resolver? Não vai! Então fique calado! Eu prefiro que pegue na minha mão e fique calado do meu lado, entendeu? (Urânio, 64 anos).

Nesse sentido, as doenças crônicas, de modo geral, apresentam a característica de mediar a relação que a pessoa estabelece com o mundo. A dor pode 
demonstrar o quanto à presença de uma doença persistente pode gerar sofrimento psicológico e interferir na relação que estabelecemos com o mundo, impondo desafios cotidianos, na relação consigo e com o outro (Santos, Giancomin \& Firmo, 2015).

Aspectos psicológicos também são enfatizados nas queixas dolorosas, visto que, sintomas e transtornos de ansiedade e depressão são muito significativos em todo o processo de adoecimento e são agravados por tensão e apreensão diante do quadro álgico. Especialmente as pessoas com doenças crônicas, que necessitam de tratamento contínuo e por períodos prolongados, apresentam alterações significativas no humor e na qualidade de vida, o que influencia diretamente nas relações sociais, nas atividades de vida diária, no sono e apetite (Castro et al., 2011).

Nos relatos dos pacientes também foi possível observar outro sentido conferido à dor. A relação causal estabelecida foi a de que relacionamentos interpessoais mal sucedidos influenciaram no processo de adoecimento e dor crônica:

Eu acho, assim, que o que também me levou mais isso aí, foi uma decepção que eu tive do último relacionamento que eu tive, entendeu? (...) e foi quando eu comecei a saber desse problema da minha doença do câncer (Ametista, 66 anos).

Eu era uma mulher muito sadia, né? Mas depois de uns tempo, me estressei com o marido, aí assim, fiquei com diabete, pressão alta, aí depois o sangue não tava circulando nas perna, aí fiz uma cirurgia tem um mês e pouco, vascular... aí depois no são João comecei a sangrar, sangrou muito né, já era da doença do câncer, né? (Esmeralda, 62 anos)

Nas narrativas dos pacientes, observa-se que a crise conjugal se configura como um fator diretamente relacionado ao adoecimento e o quanto este adoecer se articula com diversas dimensões da vida. Uma variedade de aspectos relaciona-se ao contexto de surgimento da dor. Alguns eventos desestabilizadores para o sujeito como o desemprego, processo de luto, bem como problemas familiares e conjugais podem ser disparadores do processo de um adoecimento, bem como acentuar a dor crônica (Palmeira et al., 2015).

A experiência de dor envolve nomear a origem do sofrimento, o que implica em ter condições para aliviar a dor e saber a direção a tomar em relação a este sofrimento. Logo, o surgimento do adoecimento e da dor, por vezes, é atribuído ao próprio envelhecimento e suas mudanças orgânicas, como também encontra expressão na culpabilização de pessoas e/ ou eventos de vida, como observado nos relatos anteriores (Santos, Giancomin \& Firmo, 2015). Nessa procura por uma resposta ou fator causador, configura-se uma busca, nem sempre verbalizada pelo sujeito, por uma possível causa para o adoecimento. Portanto, a simbolização e a busca por dar significação ao adoecimento é algo frequente entre as pessoas com dor crônica, fazendo referência a eventos de vida que representam perdas (Santos, Giancomin \& Firmo, 2015).

\section{Dor, Solidão e Isolamento: Uma Via de Mão Dupla}

A dor crônica influencia não somente na relação que cada pessoa estabelece consigo, como também gera efeitos nas relações sociais e familiares, altera o cotidiano e pode produzir sensação de solidão e gerar isolamento (Pereira et al, 2014). Neste sentido, a dor conduz a novas formas deste sujeito se relacionar com o mundo, uma vez que há uma completa modificação na forma de lidar com sua rotina, alterada pela presença da doença, tratamentos e dor, podendo levar a pessoa a ter uma vida mais restrita nas suas atividades habituais.

Tal situação pode levar o sujeito a um questionamento intenso da própria identidade, considerando que a sociedade está pouco organizada para a participação e inclusão das pessoas que adoeceram e que precisam de formas mais específicas para se inserirem no trabalho, na reorganização das atividades diárias, e na retomada da autonomia. Deste modo, o sujeito pode sofrer não apenas da dor, mas do isolamento que essa circunstância causa (Pereira et al, 2014; Sallum, Garcia \& Sanches, 2012).

As dimensões de isolamento e solidão aparecem nas falas de alguns dos pacientes entrevistados, com diferentes sentidos. No relato da paciente Ametista, a solidão é enfatizada como um fator intensificador da dor:

A dor aumenta quando a gente tá sozinha, com tipo um desprezo, se achando isolado, entendeu? Ai é triste, eu acho que ai é que a gente se acaba mais rápido, quando a gente se sente tipo como 
se a gente tivesse abandonado por alguém, entendeu? (Ametista, 66 anos)

Já em outras narrativas, o distanciamento social e a resposta de isolamento podem ser sugestivos de estratégia passiva (disfuncional) para lidar com a dor:

(...) com dor eu prefiro ficar calado, em silêncio, que as pessoas não conversem, me deixem quietinho, entendeu? (...) pode até alguém ficar comigo, nem faço questão, mas se ficar, que não fique me perguntando besteira (Urânio, 64 anos).

Eu guento dor no calado. Passo o dia tooodo sem ninguém nem saber. Passava o dia todo sentindo dor, trabalhando, fazendo tudo calada. Gosto de tá só. Isso

é um problema sério, né? Quero ficar só o dia todo quando tô com dor (Magnetita, 60 anos).

O uso das estratégias de enfrentamento resulta da ocorrência de eventos estressantes. Tais eventos por si só, não determinam as consequências negativas para as pessoas, pois dependem da avaliação cognitiva sobre a demanda que estes eventos exercem sobre a vida do sujeito. Na população idosa, há grande variabilidade nas formas de enfrentamento dos eventos estressantes, uma vez que estão expostos a diferentes circunstâncias de seu contexto pessoal, além de possuírem diferentes níveis de resiliência e uma forma particular de interpretar e lidar com as situações estressantes com as quais convivem (Horta, Ferreira \& Zhao , 2010; Fortes-Burgos, Neri \& Cupertino, 2008).

Deste modo, a escolha das estratégias de enfrentamento depende da percepção e da avaliação da situação estressora em que o sujeito se encontra e pode ter como consequência resultados melhores ou piores do que a situação inicial. Dentre o repertório de estratégias de enfrentamento utilizados pelos indivíduos, pode-se encontrar o enfrentamento confrontativo, a busca de suporte social ou distanciamento social, fuga-esquiva, inibição das emoções, reavaliação positiva, enfrentamento religioso, busca de informações, entre outros (Ottati \& Campos, 2014).

Nos relatos de Urânio e Magnetita, a resposta do silêncio diante da dor e o desejo de estar só e não ser incomodado evidencia a forma como lidam com o evento estressor que é processo álgico no qual vivenciam. Tal estratégia parece ser funcional para ambos; no entanto, é importante estar atento aos impactos psicossociais de tais estratégias e as repercussões na rotina e dinâmica familiar, pois estas não são estratégias funcionais e adequadas e produzem consequências significativas que corroboram com a piora do quadro doloroso. Tendo em vista que cada fase do tratamento oncológico se configura como um evento estressor, e a forma como o paciente lida com o problema influencia na adaptação a nova fase, é importante que as práticas terapêuticas sejam direcionadas a auxiliar na adaptação do indivíduo à nova realidade, bem como no uso adequado de estratégias de enfrentamento (Ottati \& Campos, 2014).

Conforme discute Palmeira (2015), a dificuldade em compartilhar sobre as vivências de dor e a sua deslegitimação social, são aspectos que a literatura pontua nos estudos sobre significados, enfatizando a dimensão da individualização da dor, bem como a ideia de solidão, isolamento e incertezas quanto ao futuro. A dor pode restringir a pessoa a si mesmo, configurando-se como uma vivência solitária e sem mediação social, empobrecendo a interlocução com o outro. Isso gera, por sua vez, a sensação de isolamento da pessoa e compromete sua linguagem e a capacidade de comunicação da dor no campo social (Santos, Giancomin \& Firmo, 2015).

Diante dos possíveis impactos do isolamento social dos indivíduos com dor, os objetivos terapêuticos devem considerar a importância do resgate das atividades cotidianas, estabelecimento de uma nova função social, a fim de que possa minimizar o isolamento social do indivíduo, apesar da permanência da dor. Estes aspectos deslocam a dor como aspecto central da vida e a coloca em uma margem talvez controlável (Lima \& Trad, 2007). É importante estar atento a tais aspectos, de modo que o cuidado ao doente crônico seja efetivado, minimizando, assim os impactos do isolamento de quem sente a dor e criando espaços para a simbolização e significação da vivência álgica na velhice e no contexto oncológico.

\section{Dor, Religiosidade e Espiritualidade: Uma Busca de Caminho Fora da Ciência}

O tema da espiritualidade e religiosidade como estratégia de enfrentamento nos contextos de saúde e doença dos indivíduos, tem sido bastante discutido pela literatura. A espiritualidade é a dimensão peculiar do ser humano que o impulsiona na busca do sagrado, da experiência transcendente, na tentativa de dar sentido e resposta aos aspectos fundamentais 
da vida; envolve a possibilidade de mergulhar em si mesmo. A religiosidade, por sua vez, é a expressão ou prática que pode estar relacionada a uma instituição religiosa e se configura como expressão da própria espiritualidade (Gomes, Farina \& Dal Forno, 2014).

A religiosidade e a espiritualidade são estratégias de enfrentamento mais utilizadas em situações de crises causadas por problemas de saúde e, de modo geral, possuem efeitos benéficos no controle e na cura de doenças. Para expressiva parte da população idosa, as questões relativas ao divino e o sagrado representam um meio relevante de lidar com os eventos estressantes, principalmente diante da possibilidade da dependência completa de outras pessoas (Pereira, Firmo \& Giancomin, 2014).

O conceito de enfrentamento religioso definido a partir do estudo cognitivista do estresse e do coping é compreendido como uma transação interativa na qual pessoa e ambiente estabelecem relações dinâmicas e recíprocas. (Santos, Giacomin, Pereira \& Firmo, 2013). Tais estratégias podem ser classificadas como positivas ou negativas, dependendo dos efeitos gerados na saúde física e mental, e conforme contribuam na adesão ao tratamento terapêutico. O uso significativo destas estratégias pode revelar a carência de outros recursos e de alternativas concretas de apoio e de intervenção nos casos de problemas de saúde (Pereira, Firmo \& Giancomin, 2014).

A dimensão da religiosidade e espiritualidade foi o aspecto pontuado por todos os participantes como estratégia de enfrentamento utilizada na experiência de adoecimento e dor, corroborando o que a literatura pontua acerca da relevância e expressividade do enfrentamento religioso.

ah, na hora que a dor comia, eu fazia minhas oração, pedia muito a Deus, botava meu joelho no chão e pedia

(...) falava com Deus que eu não aceitava tá passando por isso, entendeu? Sempre pedia assim, com aquele coração, na minha maneira de pedir. Eu usava isso como uma forma de melhoramento pra mim, e Deus, sempre que eu peço, graças a Deus, eu tudo na vida que eu já pedi, eu alcanço. Acho que eu busco com tanta fé, que aquilo acontece, entendeu? (Ametista, 66 anos)

Tenho muita fé em Deus! Eu já passei pela do coração, agora vem essa outra do caroço (...) então Jesus vai me curar; se já passei por duas, passo por três, né, não?

(Esmeralda, 62 anos)
Um estudo de Folkman, Lazarus, Pimley \& Novacek (1987), baseado na teoria do estresse e do coping, demonstrou que pessoas idosas tendem a utilizar com maior frequência, estratégias de enfrentamento com foco nas emoções comparado as outras faixas etárias. Outros estudos revelam que a partir da meia-idade os sujeitos valorizam mais os aspectos internos do self, possibilitando encontro com os sentimentos e fortalecendo comportamentos religiosos (Santos, Giacomin, Pereira \& Firmo, 2013).

Deste modo, o enfrentamento religioso funciona como mediador entre as aflições, o medo, as tragédias e a realidade de quem envelhece e, especialmente, de quem convive com a incapacidade atual ou com o temor de que ela lhe ocorra no futuro (Vivan \& Argimon, 2009).

Através deste enfrentamento, os sujeitos buscam explicações que extrapolam o biológico e o científico, e se remetem a aspectos sobrenaturais. Nestes casos, a expectativa de cura pode deixar de se apoiar nos meios técnicos e científicos para estar direcionado a uma cura de ordem religiosa/espiritual, através da qual o paciente busca o sagrado para controlar algo que não pode ser controlado, uma vez que a proximidade da finitude torna-se mais evidente (Reis, Farias \& Quintana, 2017).

Além destes aspectos, a cultura da sociedade reforça o não enfrentamento direto das dificuldades; neste sentido, a religiosidade intensifica este aspecto, na medida em que, não havendo outras alternativas, produz no sujeito passividade e conformismo (Santos et al., 2013). Este aspecto fica implícito nas falas que apresentam a ideia de que Deus é quem quer que as coisas aconteçam desta maneira, naturalizando o processo de adoecimento e associando o envelhecimento à incapacidade. Este aspecto é ressaltado por Esmeralda ao relatar: “Mas é assim mesmo né? Deus é quem quer!". Também é salientado na seguinte narrativa:

Tem que ter fé em Deus, que Jesus é maravilhoso (...) Nesse mundo véi, nós tem que aguentar tudo, com muita calma, com muita fé em Deus. Se Deus quer, nós só pode aceitar, né mesmo? (Magnetita, 60 anos)

A espiritualidade no enfrentamento do câncer e sua influência na qualidade de vida são discutidas por Miranda, Lana e Felippe (2015). Estes citam estudos realizados com pacientes idosos com câncer, onde o 
bem-estar espiritual significou um fator de proteção positivo no combate à enfermidade e a ansiedade nos pacientes que declararam ter alguma fé religiosa. Portanto, é importante valorizar a dimensão espiritual no ambiente hospitalar, de modo que possibilite melhorias nas condições de saúde e na qualidade de vida dos pacientes que utilizam esta estratégia. $O$ paciente Ametrino pontua sobre sua rotina de meditação no hospital e cita a diminuição da ansiedade decorrente da sua prática religiosa, bem como o apoio dos profissionais e demais pacientes:

(...) tenho uma filosofia de não me estressar. Como eu lhe disse, o pensamento budista me leva ao relaxamento, a meditação, a calma. Geralmente consigo me concentrar aqui no hospital... aí quando acordo, faço minhas orações, meus mantra e me aquieto, e aí fico menos ansioso. Isto me ajuda a seguir, porque viver com câncer e a dor não é fácil. $E$ todo mundo daqui já sabe, e respeita meus horários

(Ametrino, 66 anos).

O paciente Urânio também explicita a importância da sua crença religiosa, como estratégia de enfrentamento no processo de tratamento oncológico.

Olha (...) na verdade eu tenho rezado muito, entendeu? Quando eu vou fazer a radioterapia, também que é um outro momento que incomoda bastante, eu rezo bastante quando eu tô deitado lá...eu sou católico, e aí eu rezo muito, eu rezo meus Pai Nosso, meus Ave Maria, meus Salve Rainha, meus crendêspai, e tal e tal e tal e me sinto melhor (Urânio, 64 anos)

Este também enfatiza a importância do apoio familiar, bem como ressalta a relevância de ter alguma crença, algo superior em que se apegar, como meio de fortalecimento e enfrentamento.

Em casa a gente ficava o dia todo rezando, televisão ligada em televisão católica, missa, novena. o pessoal da família tem muita gente que faz novena, tem muita gente evangélica também que pede ao pastor pra rezar, e toda fé é bem vinda e me ajuda. Também sou simpatizante do Espiritismo (...) Cê tem que acreditar em alguma coisa. Isso te fortalece, saber que tem alguma coisa por trás que dá um conforto. Eu, por exemplo, converso com a Irmã Dulce direto (Urânio, 64 anos).

Nesse sentido, observa-se que a religiosidade e a espiritualidade ocupam um lugar de importância na vida dos pacientes, compondo a realidade do adoecimento destes e contribuindo para amenizar os impactos negativos advindos da cronicidade do adoecimento.

Portanto, o entendimento do papel do enfrentamento religioso no tratamento oncológico é relevante, pois pode possibilitar aos profissionais de saúde meios de viabilizar e operacionalizar as crenças dos sujeitos, através da facilitação das práticas religiosas que sejam funcionais ao tratamento. Esta pode ser uma estratégia no âmbito da saúde que aumente a qualidade de vida, adesão ao tratamento e contribua para o bem estar subjetivo do indivíduo.

\section{Considerações finais}

A dor crônica, devido a suas especificidades, pode influenciar em diferentes dimensões da vida do ser humano que a experimenta, incluindo as relações sociais e familiares, o humor, as atividades diárias e o mundo do trabalho. Deste modo, os indivíduos podem encarar com dificuldade o adoecimento e a vivência álgica, requerendo destes, atitudes e modos de enfrentamento adaptativos. Neste sentido, este estudo se propôs a compreender as percepções e subjetividade de idosos hospitalizados acerca da dor crônica e o modo como lidam com as dificuldades impostas pelo próprio adoecimento.

A partir das análises das narrativas, observa-se que os participantes significam a experiência de dor como uma vivência negativa, que os afeta diretamente e influencia, sobretudo, nas relações sociais, gerando e intensificando o isolamento e sentimentos de irritação. Como meio de enfrentamento a tais situações, a religiosidade e espiritualidade se destacam, sendo uma forma de minimizar os impactos negativos advindos do adoecimento e tratamentos contínuos.

Portanto, estudar tais aspectos é importante à medida que o entendimento da maneira de enfrentamento da dor pelo idoso pode auxiliar profissionais de saúde na análise de fatores que influenciam na mesma, assim como na adequação de possíveis estratégias de enfrentamento disfuncionais no contexto de saúde, auxiliando o idoso no tratamento e em sua qualidade de vida. Deste modo, nas práticas de saúde e no gerenciamento e tratamento da dor crônica deve-se contemplar múltiplos aspectos da vida da pessoa adoecida, considerando o fato da dor do 
paciente não ser um fenômeno único, mas é sempre multidimensional, com numerosas variáveis afetivas, emocionais, cognitivas e comportamentais que interagem entre si.

\section{Contribuição das autoras}

Castro MMC participou como orientadora da pesquisa, instruindo e orientando quanto à revisão de literatura, ao processo de coleta de dados, bem como a estruturação do artigo e revisão ortográfica do texto. Santos NRP participou como pesquisadora, coletando os dados da pesquisa, transcrevendo-os e interpretando-os à luz do referencial teórico citado no artigo. Também cooperou na redação do texto e realizou as revisões de literatura indicadas pela orientadora, bem como ficou responsável pelo encaminhamento do artigo científico para a presente revista.

\section{Conflitos de interesses}

Nenhum conflito financeiro, legal ou político envolvendo terceiros (governo, empresas e fundações privadas, etc.) foi declarado para nenhum aspecto do trabalho submetido (incluindo mas não limitando-se a subvenções e financiamentos, participação em conselho consultivo, desenho de estudo, preparação de manuscrito, análise estatística, etc.).

\section{Referências}

Angerami-Camon, V. A. (2012). Psicossomática e a psicologia da dor. São Paulo: Pioneira Thomson Learning.

Bardin, L. (2011). Análise de Conteúdo. São Paulo: Edições 70.

Castro, M. M. C., Quarantini, L. C., Daltro, C., Pires-Caldas, M., Koenen, K. C., Kraychete, D. C., \& Oliveira, I. R. (2011). Comorbidade de sintomas ansiosos e depressivos em pacientes com dor crônica e o impacto sobre a qualidade de vida. Rev. psiquiatr. clín., 38(4), 126-129. Recuperado de http://www.scielo.br/pdf/rpc/v38n4/a02v38n4.pdf. doi: 10.1590/S0101-60832011000400002

Celich, K. L. S., \& Galon, C. (2009). Dor crônica em idosos e sua influência nas atividades da vida diária e convivência social. Revista Brasileira de Geriatria e Gerontologia, 12(3), 345-359. Recuperado de http://www.scielo.br/ pdf/rbgg/v12n3/1981-2256-rbgg-12-03-00345.pdf. doi: 10.1590/1809-9823.2009.00004

Chiba, T. \& Ashmawi, H. (2011). Diagnóstico e tratamento da dor. In E. V. Freitas, L. Py, F. A. X. Cançado, J. Doll, M. L. Gorzoni, Tratado de Geriatria e Gerontologia (pp. 1706-1721). São Paulo: Guanabara Koogan.
Dellaroza, M. S. G., Furuya, R. K., Cabrera, M. A. S., Matsuo, T., Trelha, C., Yamada, K, N., ... Pacola, L. (2008). Caracterização da dor crônica e métodos analgésicos utilizados por idosos da comunidade. Revista da Associação Médica Brasileira, 54(1), 36-41. Recuperado de http://www. scielo.br/pdf/ramb/v54n1/18.pdf. doi: 10.1590/5010442302008000100018

Duarte, R. C., \& Nogueira-Costa, R. (2011). Tratamento do Paciente Geriátrico Portador de Câncer. In: E. V. Freitas, L. Py, F. A. X. Cançado, J. Doll, M. L. Gorzoni, Tratado de Geriatria e Gerontologia (pp. 1706-1721). São Paulo: Guanabara Koogan.

Folkman, S., Lazarus, R.S, Pimley, S., \& Novacek J. (1987). Age Differences in Stress and Coping Processes. Psychol Aging, 2(2), 171-184.

Fortes-Burgos, A. C. G, Neri, A. L., \& Cupertino, A. P. F. B. (2008). Eventos estressantes, estratégias de enfrentamento, autoeficácia e sintomas depressivos entre idosos residentes na comunidade. Psicologia: Reflexão e Crítica, 21(1), 74-82. Recuperado de http://www.scielo.br/pdf/prc/v21n1/ a10v21n1.pdf. doi: 10.1590/S0102-79722008000100010

Gomes, N. S., Farina, M., \& Dal Forno, C. (2014). Espiritualidade, Religiosidade e Religião: Reflexão de Conceitos em Artigos Psicológicos. Revista de Psicologia da IMED, 6(2), 107-112. Recuperado de https://seer.imed.edu.br/index.php/ revistapsico/article/view/589/484. doi: 10.18256/2175$\underline{5027}$

Horta, A. L. M., Ferreira, D. C. O., \& Zhao, L. M. (2010). Envelhecimento, estratégias de enfrentamento e repercussões na família. Revista Brasileira de Enfermagem, 63(4), 523-528. Recuperado de http://www.scielo. br/pdf/reben/v63n4/04.pdf. doi: 10.1590/S003471672010000400004

Internacional Association for the Study of Pain (2007). Recuperado de http://www.iasp-pain.org.

Lazarus, R. S., \& Folkman, S. (1984). Stress, appraisal and coping. New York: Springer Publishing.

Lima, M. A. G., \& Trad, L. A. B. (2007). A dor crônica sob o olhar médico: modelo biomédico e prática clínica. Cadernos de Saúde Pública, 23(11), 2672-2680. Recuperado de http:// www.scielo.br/pdf/csp/v23n11/14.pdf. doi: 10.1590/s0102311X2007001100015

Lima, M. A. G., \& Trad, L. (2008). Dor crônica: objeto insubordinado. História, Ciências, Saúde Manguinhos, 15(1), 117-133. Recuperado de http://www.scielo.br/pdf/hcsm/ v15n1/07.pdf. doi: 10.1590/S0104-59702008000100007 
Loduca, A., Müller, B. M., Amaral, R., Souza, A. C. M. S., Focosi, A. S., Samuelian, C., ... Batista, M. (2014). Retrato de dores crônicas: percepção da dor através do olhar dos sofredores. Revista Dor, 15(1), 30-35. Recuperado de http://www.scielo.br/pdf/rdor/v15n1/1806-0013rdor-15-01-0030.pdf. doi: 10.5935/1806-0013.20140008

Minayo, M. C.S. (2010). O desafio do conhecimento: pesquisa qualitativa em saúde. São Paulo: HUCITEC.

Ministério da Saúde. Secretaria de Atenção à Saúde. Instituto Nacional de Câncer. Coordenação de Prevenção e Vigilância (2006). A situação do câncer no Brasil. Recuperado de http://bvsms.saude.gov.br/bvs/ publicacoes/situacao_cancer_brasil.pdf

Miranda, S. L., Lanna, M. A. L., \& Felippe, W. C. (2015). Espiritualidade, Depressão e Qualidade de Vida no Enfrentamento do Câncer: Estudo Exploratório. Psicologia: Ciência e Profissão, 35(3), 870-885. Recuperado de http://www.scielo.br/scielo.php?script=sci_ arttext\&pid=S1414-98932015000300870. doi: 10.1590/1982-3703002342013

Ottati, F., \& Campos, M. P. S. (2014). Qualidade de vida e estratégias de enfrentamento de pacientes em tratamento oncológico. Acta Colombiana de Psicología, 17(2), 103-111. Recuperado de http://www.scielo.org.co/pdf/acp/v17n2/ v17n2a11.pdf. doi: 10.14718/ACP.2014.17.2.11

Palmeira, A. T., Iriart, J., Castellanos, M., Lima, M. A. G., Barros, N, F., \& Menezes, P. F. A. (2015). Narrativa sobre dor crônica: da construção do adoecimento à organização da vida com dor. In M. E. P. Castellanos, L. A. B. Trad, M. S. B. Jorge, \& I. M. T. A. Leitão (Orgs.). Cronicidade: experiência de adoecimento e cuidado sob a ótica das ciências sociais (pp. 300-338). Fortaleza: EdUECE.

Palmeira, A. T. (2015). Experiência de enfermidade em pessoas com dor crônica atendidas em um serviço especializado de saúde (Tese de doutorado). Universidade Federal da Bahia, Salvador, BA, Brasil. Recuperado de https:// repositorio.ufba.br/ri/bitstream/ri/17921/1/TESE.\%20 Aline\%20Palmeira.\%202015.pdf

Pereira, J. K., Firmo, J. O. A., \& Giacomin, K. C. (2014). Maneiras de pensar e de agir de idosos frente às questões relativas à funcionalidade/incapacidade. Ciência \& Saúde Coletiva, 19(8), 3375-3384. Recuperado de http://www.scielo. br/pdf/csc/v19n8/1413-8123-csc-19-08-03375.pdf. doi: 10.1590/1413-81232014198.11942013

Pereira, L. V., Vasconcelos, P. P., Souza L. A. F., Pereira, G. A., Nakatani, A. Y. K., \& Bachion, M. M. (2014). Prevalência, intensidade de dor crônica e autopercepção de saúde entre idosos: estudo de base populacional. Revista LatinoAmericana de Enfermagem, 22(4), 662-669. Recuperado de http://www.scielo.br/pdf/rlae/v22n4/pt_0104-1169rlae-22-04-00662.pdf. doi: 10.1590/0104-1169.3591.2465
Resolução 466/12, de 12 de dezembro de 2012. Dispõe sobre as diretrizes e normas regulamentadoras de pesquisas envolvendo seres humanos. Recuperado de http://bvsms.saude.gov.br/bvs/saudelegis/cns/2013/ res0466_12_12_2012.html

Reis, C. G. C., Farias, C. P., Quintana, A. M. (2017). O Vazio de Sentido: Suporte da Religiosidade para Pacientes com Câncer Avançado, Psicologia: Ciência e Profissão, 37(1), 106-118. Recuperado de http://www.scielo.br/pdf/pcp/ v37n1/1982-3703-pcp-37-1-0106.pdf. doi: 10.1590/19823703000072015

Reticena, K. O., Beuter, M., \& Sales, C. A. Vivências de idosos com a dor oncológica: abordagem compreensiva existencial. Revista da Escola de Enfermagem da USP, 49(3), 419-425. Recuperado em http://www.scielo.br/pdf/reeusp/v49n3/ pt_0080-6234-reeusp-49-03-0419.pdf. doi: 10.1590/S0080$\underline{623420150000300009}$

Sallum, A. M. C., Garcia, D. M., \& Sanches, M. (2012). Dor aguda e crônica: revisão narrativa da literatura. Acta Paul Enferm., 25(1), 150-154. Recuperado de http://www.scielo. br/pdf/ape/v25nspe1/pt_23.pdf. doi: 10.1590/S0103$\underline{21002012000800023}$

Salvetti, M. G., \& Pimenta, C. A. M. (2007). Dor crônica e a crença de auto-eficácia. Revista da Escola de Enfermagem da USP, 41(1), 135-140. Recuperado de http://www.scielo.br/ pdf/reeusp/v41n1/v41n1a17.pdf. doi: 10.1590/S0080$\underline{62342007000100018}$

Santos,W. J., Giacomin, K. C. \& Firmo, J. O. (2015). A Alteridade da dor nas práticas de Saúde Coletiva: implicações para a atenção à saúde de pessoas idosas. Ciência \& Saúde Coletiva, 20(12), 3713-3721. Recuperado de http://www. scielo.br/pdf/csc/v20n12/en_1413-8123-csc-20-12-3713. pdf. doi: 10.1590/1413-812320152012.19382014

Santos, W. J., Giacomin, K. C., Pereira, J. K., \& Firmo, J. O. A. (2013). Enfrentamento da incapacidade funcional por idosos por meio de crenças religiosas. Ciência \& Saúde Coletiva, 18(8), 2319-2328. Recuperado de http://www.scielo.br/pdf/csc/ v18n8/16.pdf. doi: 10.1590/S1413-81232013000800016

Vivan, A. S., Argimon, I. I. L. (2009). Estratégias de enfrentamento, dificuldades funcionais e fatores associados em idosos institucionalizados. Caderno Saude Publica, 25(2), 436-44. Recuperado de http://www.scielo.br/pdf/csp/v25n2/22. pdf. doi: 10.1590/S0102-311X2009000200022 